\title{
Histoplasmosis in Cyprus: Report of Two Cases
}

\author{
D. J. STOKER,* M.B., M.R.C.P.
}

Brit. med. F., 1964, 2, 793-795

Since the observation of a new micro-organism by Darling in 1905 (Darling, 1906) and its discovery at necropsy in three cases clinically resembling kala-azar (Darling, 1908), numerous cases of histoplasmosis have been described. The first case to be described clinically was that of a Tennessee infant with splenomegaly and anaemia (Dodd and Tompkins, 1934). Demonbreun (1934) cultured Histoplasma capsulatum from this infant's blood before and after death and demonstrated the fungal aetiology of the infection.

More than half the reported cases of histoplasmosis have been in people resident in the United States of America, and especially in the North-east, Central, and South Central States. Histoplasmosis is no longer the rare fatal disease it was once thought to be, for only a small proportion of persons infected develop symptomatic illness. It has been estimated that 25-30 million people in the United States have experienced some form of histoplasma infection (Loosli, 1955). More than half the cases of histoplasmosis reported outside North America have been in Central and South America. The two other principal endemic areas are Africa (Central and South) and the Far East (Philippines, Indonesia, and Australia) (Edwards and Klær, 1956).

Of the 95 cases reported during 1906-55, only six occurred in Great Britain, and all but one of these had for some period been resident in Africa or the Far East. Studies in England, Greece, and Turkey all show less than $2 \%$ positive reactors to the histoplasmin skin test (Edwards and Klær, 1956). The sole report of histoplasmin skin-testing in Cyprus showed only $2.2 \%$ of reactions of $6 \mathrm{~mm}$. or above in the inhabitants of the village of Kormakiti (Edwards et al., 1956). I can find no published report of a case of histoplasmosis occurring in Cyprus, and in consequence the following account of illness due to that infection occurring in two Britons while resident in Cyprus is noteworthy for that reason and because one of the patients developed encephalitis.

The two patients were members of a party visiting a labyrinth in the ancient Roman settlement of Curium, in Southern Cyprus, in the middle of February 1960. Still air conditions prevailed inside the cave, but the floor was dusty. One of the party (Case 1) noticed a large bat hanging from the roof, wrapped it in his handkerchief, and showed it to his companion (Case 2), who held it briefly. The bat was then replaced, the first patient shook out his handkerchief but used it occasionally during the rest of the expedition to mop his brow. No other member of the party came near the bat and none subsequently developed a clinical illness, though chest $x$-ray examinations and histoplasmin sensitivity tests were not performed.

\section{Case 1}

A Royal Air Force officer aged 41 first became unwell towards the end of February 1960. He sweated profusely, felt cold and shivery, and went to bed at home. Over the next few days he had several febrile episodes but no other symptoms, except for diarrhoea and vomiting lasting 24 hours. He returned to work, but in another five days his fever returned, this time accompanied by dyspnoea and aching in the lower limbs. His malaise continued and he visited the doctor again on 24 March 1960, when chest $x$-ray

* Wing Commander, Royal Air Force. Present address : Metabolic Unit, St. Mary's Hospital, Paddington. examination showed coarse miliary mottling throughout the lung fields (Fig. 1).

He was admitted to hospital on 24 March, at which time his temperature was $100.6^{\circ} \mathrm{F} .\left(38.1^{\circ} \mathrm{C}\right.$.). Examination of the chest revealed bronchial breathing in the right mid-zone posteriorly. A few small glands were palpable in the left axilla, but otherwise there were no positive physical signs. E.S.R. was $50 \mathrm{~mm}$. in one hour (Westergren). Mantoux 1/3,000 old tuberculin (3 T.U.) was positive. Sputum showed no growth on routine culture; no acid/ alcohol-fast bacilli were seen on direct examination or on culture. Histoplasmin skin test was strongly positive $(14 \mathrm{~mm}$.). Coccidioidin skin test was negative. No facilities for histoplasmin complement fixation were available at this time.

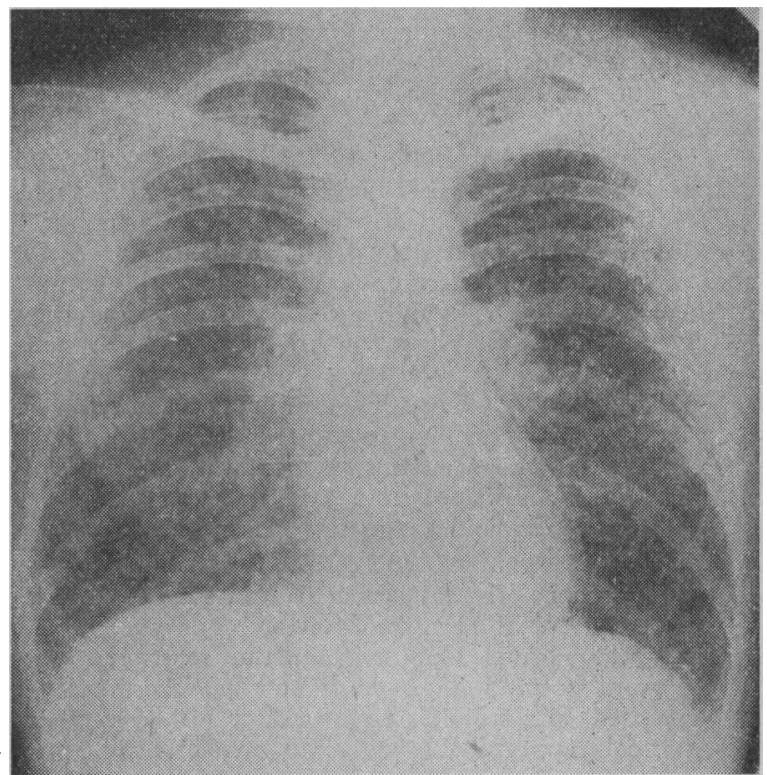

Fig. 1.-Case 1. Chest $x$-ray film taken on $24 \mathrm{March}, 1960$.

When admitted he felt well, but remained pyrexial for six days. At the time of discharge from hospital on 11 April the shadows seen in his chest $x$-ray film were starting to clear and by 28 June $x$-ray appearances were normal.

However, on 19 June he experienced aching in the region of both hips and down the back of both thighs, followed two days later by stiffness in his back and neck. On 24 June he developed aching of his jaw, with increasing difficulty in opening his mouth On readmission to hospital his speech was noted to be indistinct owing to paresis of facial muscles. The next day this had progressed to a bilateral lower-motor-neurone facial paralysis. In addition the skin overlying both malar bones showed loss of sensation to pin-prick and there was some blurring of vision on conjugate deviation of his eyes to the left.

A small tender lymph node was palpable behind the angle of the jaw on the left side. No stiffness of the neck was demonstrated and Kernig's sign was not present. Examination of other systems showed nothing abnormal.

Cerebrospinal fluid was examined on the third day after readmission and was found to be clear and under normal pressure ; cells, $250 /$ c.mm., all lymphocytes; protein $90 \mathrm{mg} . / 100 \mathrm{ml}$.; culture sterile.

Over the next week there was a gradual return of function to the muscles of the right side of his face and the cervical lymph node ceased to be tender and eventually was no longer palpable. 
During convalescence he experienced occasional paraesthesiae of face and scalp, and slight impairment of memory and concentration.

The left facial paresis slowly improved but persisted to some degree until 1963. When he was last reviewed, on 13 November 1963 , no abnormality of facial movement could be demonstrated. His chest $x$-ray picture remained clear with, so far, no evidence of pulmonary calcification. A histoplasmin complement-fixation test was positive $1: 10$ at this time.

\section{Case 2}

At the time of onset of her illness, this patient, the 33-year-old wife of a Royal Air Force officer, was already in hospital. She had a history of acute pyelonephritis in 1951 and 1959, and laparotomies had been performed in 1955 and 1956. At the latter of these laparotomies a by-pass operation had been carried out for subacute intestinal obstruction.

For several months before admission she had experienced prostrating fatigue at certain times of the day necessitating cancellation of social engagements and giving up all swimming, whereas previously she had been a sub-aqua enthusiast.

In November 1959 she had developed right loin pain and tenderness without dysuria and was prescribed prophylactic sulphamethizole. She took this irregularly and it was discontinued on 29 January 1960 . On 10 March 1960 she began to feel unwell and giddy. She sweated profusely and at first had right loin pain. As a result she thought it was a recurrence of her previous renal complaint, but contrary to its usual course the pain disappeared in 24 hours.

She was admitted to hospital on 15 March with a four-day history of malaise following a further brief loin pain, sore throat, and purulent post-nasal drip. On examination the only finding of note was tenderness of the lower pole of the right kidney. E.S.R. was $18 \mathrm{~mm}$. in one hour (Westergren). White-blood-cell count 7,500/ c.mm. (neutrophils $62 \%$, lymphocytes $38 \%$ ). Urine showed no abnormality. Sinus $x$-ray films showed normal appearances. Her temperature on admission was $100^{\circ} \mathrm{F}$. $\left(37.8^{\circ} \mathrm{C}\right.$.) and she soon developed a dry cough. Chest $x$-ray examination showed widespread coarse miliary shadows similar to those in Case 1, with enlarged hilar shadows (Fig. 2). Mantoux reaction was negative up to and including 100 T.U. Histoplasmin skin test was strongly positive (over $14 \mathrm{~mm}$.). Coccidioidin skin test was negative.

On 18 March she vomited, and on the following day complained of anorexia, occasional frontal headache, and sore eyes. Fine rales were heard at the right base on 21 March. Two days later her temperature was normal and her appetite returning. She was discharged from hospital on 2 April and her chest $x$-ray picture quickly returned to normal. A later film (10 December 1963) showed normal appearances with no evidence of pulmonary calcification.

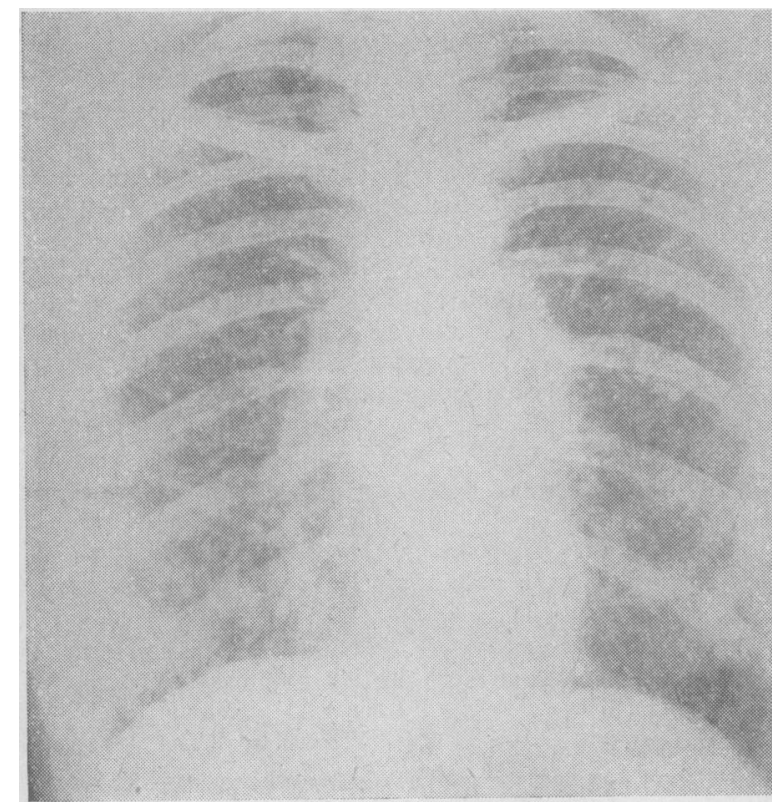

Fig. 2.-Case 2. Chest $x$-ray film taken on 25 March, 1960.
She had had a mild malabsorption syndrome due to malrotation of the intestines causing duodenal ileus. This was corrected at operation in November 1961 and cholecystectomy was performed at the same time for gall-stones.

\section{Discussion}

There is no doubt, even in the absence of the culture of the causative organism, that these two patients suffered from acute pulmonary histoplasmosis of epidemic type. As often happens, the recognition of the disease in this small group was due to the coincidence of the lesions rather than to its severity (Lehan and Furcolow, 1957). The characteristics of the disease have been well summarized before (Loosli, 1957 ; Lehan and Furcolow, 1957) and will not be repeated here. The findings in each of the above cases typified those of histoplasma in regard to the history, incubation period, clinical and radiological appearances, and skin sensitivity.

The presence of various vertebrates has been associated with the culture of Histoplasma capsulatum from the soil of places where outbreaks of histoplasmosis had occurred. Of the 41 epidemics reported by Lehan and Furcolow (1957), 12 were associated with chicken excreta, seven with pigeon excreta, and three with bat excreta. More recently, urban histoplasmosis has been related to exposure to soil contaminated by the excreta of starlings (Murdock et al., 1962). The most characteristic finding has been the relation of the disease to caves when the soil is contaminated with bat guano, and the world-wide incidence of "cave-sickness" is well reviewed by Aspin and di Bellard-Pietri (1959).

It is fairly clear that the role of bats and birds is only to provide, by their excreta, together with the warm moist atmosphere of the cave, ideal conditions for saprophytic mycelial growth of the fungus (Emmons, 1958). The natural reservoir is thought to be the soil (Loosli, 1957).

No evidence has yet been produced to show that histoplasmosis can be transmitted directly between men, animals, or men and animals (Prior and Cole, 1951 ; Christie, 1958). If this is true, then the inoculation of the two cases reported here, which was severe, as evidenced by the "snow-storm" appearances on chest $x$-ray film (Lehan and Furcolow, 1957), must have been brought about by contamination of the bat's coat with infected dust from the cave. The report of the isolation of Histoplasma capsulatum from chicken feathers stuffing a 30-year old pillow (Campbell et al., 1962) is relevant, but in that case it was possible that the pillow had been contaminated at some time after manufacture.

Involvement of the central nervous system in histoplasmosis has rarely been reported, even in the disseminated form of the disease, and has been the subject of previous reviews by Schulz (1953) and Shapiro et al. (1955), who classify the involvement into (1) miliary granulomata related to small veins in the brain, meninges, and choroid ; (2) focal destructive lesions of the brain parenchyma (histoplasmoma); and (3) meningitis, which macroscopically resembles tuberculous meningitis.

Schulz (1953) demonstrated lesions of the brain and meninges in 12 of a series of 120 cases in which necropsy was performed. The only previously reported case of histoplasma meningitis (Duarte, 1945) was not accepted as proved by Schultz.

Both Schulz and Duarte thought that further cases of central nervous involvement would be discovered if a more careful examination were made at necropsy.

The first case of histoplasma meningitis to be diagnosed in life was that reported by Sprofkin et al. (1955). Several cases have been described with a fatal outcome (Juba, 1958 ; Quiroga et al., 1962) and two with survival after treatment with amphotericin B (Nelson et al., 1961 ; Bellin et al., 1962).

Although cultural proof is lacking, it is suggested that the encephalitis in Case 2 was due to histoplasma-infection. It 
appeared before the pulmonary infection had completely cleared and was associated with probable histoplasma lymphadenitis. The only characteristic of meningitis caused by this organism appears to be the singular lack of meningeal irritation. The character of the cerebrospinal fluid is not specific, for although the sugar content is usually reduced the various authors have described counts of from 54 to 235 white cells per c.mm. and varying from $100 \%$ lymphocytes to $90 \%$ neutrophils. It is therefore quite possible that meningeal exudate was present in Case 2.

The protean nature of the neurological signs results from the scattered miliary granulomata that usually occur in the brain adjoining the meninges. Further support for the presence of a more severe and chronic histoplasmosis infection in Case 1 is given by the persistence of a positive histoplasmin complement-fixation test after nearly four years. This would be most unusual in an acute pulmonary infection which cleared radiologically in four months.

\section{Summary}

Pulmonary histoplasmosis occurring in two British subjects resident in Cyprus is reported for the first time from this locality.

The illness in both cases followed the visit to a cave where a bat was handled by both patients.

It is suggested that the subsequent encephalitis from which one of the patients made a spontaneous recovery was also due to infection by Histoplasma capsulatum.
I wish to thank Squadron-Leader M. J. Phillips for his helpful criticism of this paper, and the Director-General of the Royal Air Force Medical Services for permission to publish.

\section{REFERENCES}

Aspin, J., and di Bellard-Pietri, E. (1959). Transactions of the Cave Research Group of Great Britain, vol. 5, No. 2.

Bellin, E. L., Silva, M., and Lawyer, T. (1962). Neurology (Minneap.), 12, i 148.,

Campbell, C. C., Hill, G. B., and Falgout, B. T. (1962). Science, 136, 1050 .

Christie, A. (1958). Ann. intern. Med., 49, 544

Darling, S. T. (1906). F. Amer. med. Ass., 46, 1283.

- (1908). Arch. intern. Med., 2, 107.

Demonbreun, W. A. (1934). Amer. F. trop. Med., 14, 93.

Dodd, K., and Tompkins, E. H. (1934). Ibid., 14, 127.

Duarte, E. (1945). Mem. Inst. Osw. Cruz., 43, 457.

Edwards, P. Q., Geser, A. G., Kiølbye, E. H., Meijer, J., Christensen, O. W. (1956). Amer. F. trop. Med. Hyg., 5, 224. and Klær, J. H. (1956). Ibid., 5, 235.

Emmons, C. W. (1958). Publ. Hlth Rep. (WVash.), 73, 590

Juba, A. (1958). Psychiat. et Neurol. (Basel), 135, 260.

Lehan, P. H., and Furcolow, M. L. (1957). Y. chron. Dis., 5, 489.

Loosli, C. G. (1955). Med. Clin. N. Amer., 39, 171.

(1957). ¥. chron. Dis., 5, 473.

Murdock, W. T., Travis, R. E., Sutliff, W. D., and Ajello, L. (1962). J. Amer. med. Ass., 179, 73.

Nelson, J. D., Bates, R., and Pitchford, A. (1961). Amer. F. Dis. Child., $102,218$.

Prior, J. A., and Cole, C. R. (1951). Amer. Rev. Tuberc., 63, 538.

Quiroga, M. I., Copello, A. R., Magnin, P. H., and Somoza, M. J. (1962). Pren. méd. argent., 49, 1060.

Schulz, D. M. (1953). 7. Amer. med. Ass., 151, 549.

Shapiro, J. L., Lux, J. J., and Sprofkin, B. E. (1955). Amer. J. Path., 31, 319.

Sprofkin, B. E., Shapiro, J. L., and Lux, J. J. (1955). F. Neuropath. exp. Neurol., 14, 288.

\title{
Hormone Excretion Studies of Gynaecomastia of Puberty
}

\author{
J. W. JULL,* PH.D., B.SC.; J. A. DOSSETT, $†$ M.D.
}

Brit. med. F., 1964, 2, 795-797

Gynaecomastia in the male is an excessive mammary fibroepithelial proliferation presenting as a firm disk-like plaque beneath the nipple and areola. It may be bilateral or unilateral, and varies from small plaques just detectable by palpation to extensive structures comparable to the breasts of female adolescence. Practically without exception these epithelial proliferations of the male breast are found microscopically to be composed entirely of ducts. The frequent association of the condition with actively secreting tumours of the testis or adrenals, and the fact that similar hypertrophy follows exposure to oestrogen, either as an industrial hazard or therapeutically, has led to the assumption that gynaecomastia is the result of enhanced oestrogen levels in the body (Hall, 1959; Folley, 1960).

Some degree of gynaecomastia also occurs as a normal accompaniment of puberty in the majority of boys, when it is usually bilateral and persists for about 12 to 18 months (Hall, 1959). It has been generally assumed that pubertal gynaecomastia is due to the production of increased amounts of oestrogen, either concurrently with increase in androgen secretion or as a result of increased metabolic conversion from the elevated levels of androgen.

The following study was designed to investigate the hormonal factors concerned in the appearance of gynaecomastia

\footnotetext{
- Department of Experimental Pathology and Cancer Research, University of Leeds. Present address: Cancer Research Centre, University of British Columbia, Vancouver 8, Canada. † Department of Pathology, St. James's Hospital, Leeds.
}

of puberty, so as to evaluate the significance of the condition clinically and to gain further information concerning factors in the growth of the human breast generally. The plan was to investigate groups of boys before puberty, during puberty with and without gynaecomastia, and after puberty when the condition has regressed. It was expected that changes in oestrogen and 17-ketosteroid excretion might thus be related to the appearance and subsequent disappearance of mammary hypertrophy.

\section{Methods}

A Leeds boys' school was visited and co-operation obtained from boys aged between $10 \frac{1}{2}$ and 18 years. A medical history was taken and a physical examination made to assess development and exclude so far as possible those with a eunuchoid stature or a past or present disorder likely to be associated with gynaecomastia. The boys were classed as pre-pubertal, pubertal, or post-pubertal by examination of the size of the testes, the presence or absence of axillary, pubic, limb, and facial hair, acne, and the depth of the voice. The degree of sexual maturity was denoted by "immature," "partially mature," or "fully mature." Gynaecomastia was detected by the presence of a palpable disk beneath the nipple, the approximate size of which was noted.

Twenty-four boys, seven of whom had some degree of gynaecomastia, collected all their urine for three consecutive days. Daily specimens were stored at $4^{\circ} \mathrm{C}$., pooled for each 